\title{
CINÉTICA ENZIMÁTICA DA HIDRÓLISE DO ÓLEO DE OLIVA EM SISTEMAS BATELADA E BATELADA ALIMENTADA
}

\author{
P. S. CABRAL, M. L. CORAZZA, F.A.P.VOLL, A. ZANDONÁ \\ Universidade Federal do Paraná, Departamento de Engenharia Química \\ E-mail para contato: pah_cabrall@yahoo.com.br
}

\begin{abstract}
RESUMO - O diacilglicerol não é absorvido como gordura, podendo reduzir o teor de gordura no sangue. Desta forma, cresce o interesse na modificação dos óleos e gorduras. Na reação de hidrólise enzimática, a concentração de água é um parâmetro significativo. Assim como uma alta razão de alimentação de água/triacilglicerol é necessária para o deslocamento da reação no sentido dos produtos, o excesso de água causa o efeito de inibição reversível da enzima. O objetivo deste trabalho é avaliar a abordagem batelada alimentada em reação de hidrólise enzimática. Após 24 h de reação em batelada, o maior rendimento em ácidos graxos livres foi obtido com alimentação de $20 \% \mathrm{~m} / \mathrm{m}$ de água. Para menores tempos de reação, maiores rendimentos foram obtidos com apenas $3 \% \mathrm{~m} / \mathrm{m}$ de água. A abordagem batelada alimentada evita que a atividade enzimática seja inibida pelo excesso de água. Um modelo matemático foi ajustado aos dados experimentais, e sua capacidade de estimar perfis de reação foi validada.
\end{abstract}

\section{INTRODUÇÃO}

Dietas ricas em óleos e gorduras são fatores de risco para obesidade e doenças do coração (Cheong et al., 2007; Awadallak et al., 2013). No entanto dificilmente se conseguirá uma dieta completamente livre de gorduras, uma vez que estas conferem agradáveis características sensoriais e têm papel fundamental na alimentação por serem importantes veículos de vitaminas lipossolúveis, participarem da síntese de substâncias endógenas e serem fontes de ácidos graxos essenciais, que são sintetizados apenas por vegetais (Babicz, 2009; Blasi et al., 2007; Gioielli, 1995).

Neste contexto surge o interesse pela biotransformação destes óleos, tornando-os ricos em diacilgliceróis, que são semelhantes a triacilgliceróis quanto a digestibilidade e valor energético (Freitas et al., 2008, Maki et al., 2002). Apesar de similar ao triacilglicerol (TAG), o diacilglicerol (DAG) tem a capacidade de reduzir o nível de lipídios pósprandial, auxiliar na redução de peso e evitar o acúmulo de gordura abdominal (Cheong et al., 2007, Kruguer et al., 2011; Valério, et al., 2009; Fregolente et al., 2009). O diacilglicerol pode ser produzido através de processos de esterificação de glicerol, glicerólise de triacilgliceróis ou hidrólise parcial de triacilglicerois (Kristensen et al., 2005; Yanai et al., 2007, Castro et al., 2004).

É necessário que durante a reação de hidrólise haja uma quantidade mínima de água que envolva a enzima e hidrate o seu sítio ativo, permitindo, assim, a formação da interface necessária para que haja a ativação da lipase (Santos, 2011; Murty et al., 
2002), e no entanto é preciso que esta quantidade seja controlada para que não aconteça inibição da atividade enzimática por excesso de água (Matos et al., 2011; Pawongrat et al., 2007). Uma forma de reduzir os efeitos negativos da concentração de água, durante a hidrólise enzimática, é o emprego de sistema batelada alimentada.

Este trabalho tem como objetivo avaliar o efeito da concentração de água na cinética da hidrólise enzimática do óleo de oliva, assim como confirmar o efeito da concentração de água em um experimento com sistema semi-batelada, visando a redução do tempo de reação quando comparado a sistemas convencionais em batelada.

\section{MATERIAL E MÉTODOS}

\subsection{Materiais}

O óleo de oliva extra virgem utilizado foi da marca Andorinha, produzido em Portugal, com acidez máxima $0,8 \%$. A enzima utilizada foi LIPOZIME $^{\circledR}$ RM IM (Novozymes). Nas análises cromatográficas foram utilizados n-heptano da Biotec e grau de pureza P.A., piridina da Sigma-Aldrich e pureza P.A., derivatizante N-methy-Ntrimethysiltrifluoroacetamide (MSTFA), padrões: monooleína (pureza >99\%; CAS Number: 111-03-5), dioleína (pureza > 99\%; CAS Number: 2537-84-7), trioleína (pureza >99\%; CAS Number: 122-32-7) e ácido oleico (pureza >99\% CAS Number: 112-80-1) todos de grau cromatográfico comprados da Sigma-Aldrich.

\subsection{Métodos}

Métodos analíticos: Para determinar a acidez a amostra foi diluída em etanol absoluto em e titulou-se, sob agitação, com solução de $\mathrm{NaOH} 0,1 \mathrm{M}$ até o aparecimento de coloração rósea persistente. A acidez foi calculada em porcentagem mássica. Para análise de MAGs, DAGs, TAGs e AGLs por cromatografia gasosa, as amostras foram analisadas em cromatógrafo gasoso (GC), - Thermo Scientífic Trace 1310, com injetor automático PTV e detector de ionização de chama (FID). A coluna capilar utilizada foi Select Biodisel. As condições de operação seguiram método baseado na Norma $\mathrm{n}^{\circ}$ 14105, do Comitê Europeu para padronizações.

Métodos experimentais: Para as reações de hidrólise em sistema batelada foram adicionados a um reator de vidro encamisado $10 \mathrm{~g}$ do óleo de oliva e a quantidade de água estipulada (3\%, $10 \%$ e $20 \%$ da massa de óleo). A mistura foi submetida a agitação magnética por 1 hora para homogeneização do meio e para estabilização da temperatura. Após foi adicionado 1,36\% de enzima em relação a massa do substrato (óleo + água). Todas as reações foram deixadas sob agitação magnética por 24 horas, mantidas a temperatura constante de $55^{\circ} \mathrm{C}$ através de banho termostatizado. Ao final de 24 horas o meio reacional foi filtrado utilizando-se n-hexano e posteriormente evaporadas em rotaevaporador (Fisatom 801), para eliminação do solvente. Nas reações de hidrólise em sistema batelada alimentada a quantidade de água estipulada $(20 \% \mathrm{em}$ relação a massa de óleo) foi adicionada em pequenas quantidades ao meio reacional em intervalos de tempo de 60 minutos. Para obtenção de cinética da atividade enzimática foram realizadas reações de hidrólise, variando a concentração de água (3\%,10\% e $20 \%$ em relação a massa de óleo) e mantendo constante a quantidade de enzima $(1,36 \%$ da massa de substrato) e temperatura $\left(55^{\circ} \mathrm{C}\right)$. Para construção da curva cinética foram 
retiradas amostras a cada 4 horas e estas tituladas para determinação de acidez. A primeira amostra foi retirada após 2 horas do início da reação.

Modelo cinético da reação de hidrólise do óleo de oliva: O modelo cinético utilizado foi baseado no modelo proposto por Voll, et al. (2012). No presente trabalho foi utilizada concentração constante de enzima, assim o parâmetro de "concentração de enzima" apresentado no trabalho de Voll, et al. (2012) foi agrupado com as "taxas de constantes aparentes", resultando em novas "constantes aparentes", que são válidas para a concentração de enzima utilizada neste trabalho. Os parâmetros do modelo foram estimados a partir de ajuste do modelo aos dados experimentais através da minimização da seguinte função objetivo:

$$
f o b=\sum_{o}^{N O B S} \sum_{i}^{N C}\left(w_{i o}^{\exp }-w_{i o}^{c a l c}\right)^{2}
$$

Um algoritmo foi desenvolvido no Matlab 7.0 para o processo de estimação de parâmetros. A subrotina "ode23s" (Matlab 7.0 library tools) foi empregado para a resolução numérica das equações diferenciais e a subrotina "fminsearch" (Matlab 7.0 library tools) foi utilizado para a minimização da função objetivo. Para o ajuste dos parâmetros foram utilizados três conjuntos de dados experimentais, realizando 108 dados experimentais de concentrações de TAG, DAG, MAG e AGL.

\section{RESULTADOS E DISCUSSÃO}

\subsection{Modelagem da Cinética: Ajuste de Parâmetros}

Os valores para o desvio quadrático médio foram de 5,93\% em massa para TAG, 2,98\% em massa para DAG, 2,79\% em massa para MAG e de 2,41\% em massa para AGL. Sendo estes desvios relativamente baixos, indicam que o modelo é capaz de correlacionar os dados experimentais e descrever a hidrólise sob as condições reacionais estudadas.

\subsection{Efeito da Concentração de Água}

As Figuras 3.1, 3.2 e 3.3 mostram graficamente a boa concordância e reprodutibilidade entre os dados experimentais e o modelo cinético proposto. Pode-se observar que nos experimentos com concentrações iniciais de água mais elevadas obteve-se maior acidez final, este comportamento pode ser explicado pelo fato de que, no experimento com apenas 3\% de água em relação a massa de óleo, ao final da reação não havia água suficiente para formação da interface necessária a manutenção da atividade enzimática. Segundo Santos (2011), é necessário que durante a reação de hidrólise se tenha disponibilidade de uma quantidade mínima de água que envolva a enzima e hidrate o seu sítio ativo, o que a formação da interface local necessária para a ativação da lípase. 


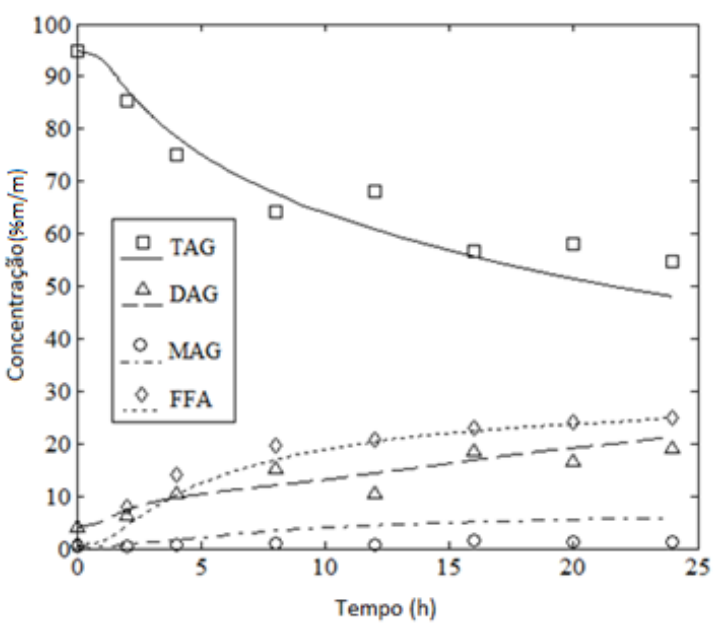

Figura 3.1 - Concentração (experimental e predita) de acilgliceróis e ácidos graxos livres obtida a partir da hidrólise parcial do óleo de oliva em função do tempo de reação a $55^{\circ} \mathrm{c} ; 1,36 \% \mathrm{~m} / \mathrm{m}$ enzima/substrato; $3 \% \mathrm{~m} / \mathrm{m}$ água/óleo.

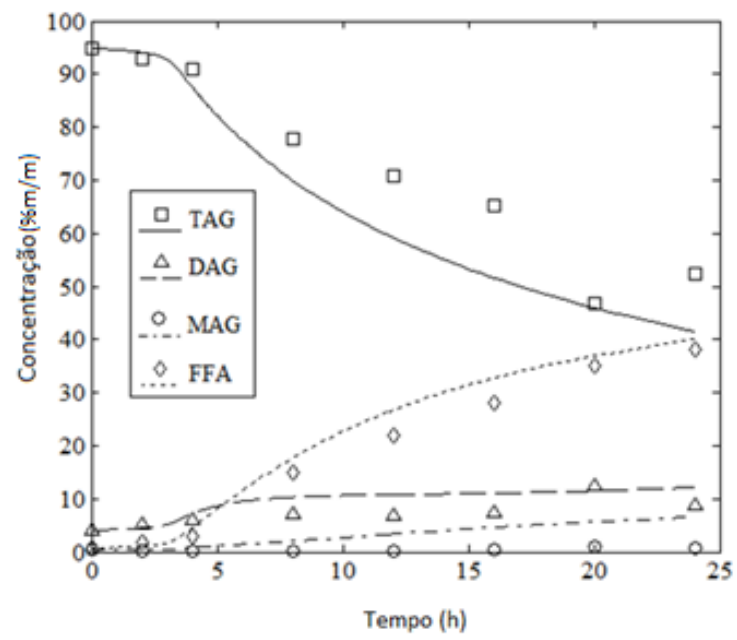

Figura 3.2 - Concentração (experimental e predita) de acilgliceróis e ácidos graxos livres obtida a partir da hidrólise parcial do óleo de oliva em função do tempo de reação a $55^{\circ} \mathrm{c} ; 1,36 \% \mathrm{~m} / \mathrm{m}$ enzima/substrato; $10 \% \mathrm{~m} / \mathrm{m}$ água/óleo.

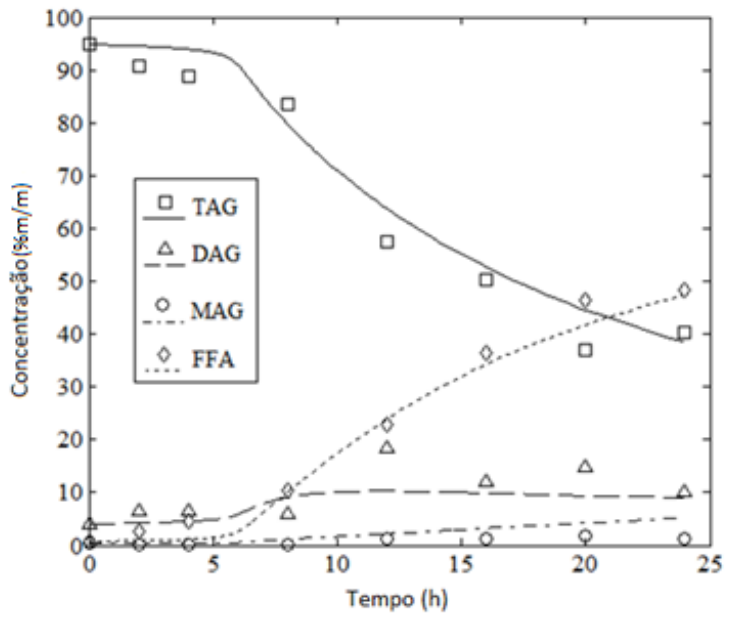

Figura 3.3 - Concentração (experimental e predita) de acilgliceróis e ácidos graxos livres obtida a partir da hidrólise parcial do óleo de oliva em função do tempo de reação a $55^{\circ} \mathrm{c} ; 1,36 \% \mathrm{~m} / \mathrm{m}$ enzima/substrato; $20 \% \mathrm{~m} / \mathrm{m}$ água/óleo. 
Ainda em relação às Figuras 3.1 - 3.3,é possível perceber que nas primeiras horas de reação uma maior acidez é obtida utilizando-se a menor concentração inicial de água. Isto porque o excesso de água reduz a velocidade da reação de hidrólise devido ao efeito de inibição reversível da enzima. O modelo cinético proposto por Voll et al. (2012) indica a existência dessa inibição. Além disso, verifica-se que o experimento com maior concentração de água (20\%) sofreu reação de hidrólise mais lenta (Figura 3.3).

Em relação às velocidades reacionais é possível observar que, ainda em relação às Figuras 3.1 - 3.3, nos três experimentos realizados não se alcançou a velocidade inicial máxima de consumo de TAG. Nas primeiras horas das reações de hidrólise enzimática do óleo de oliva, foi observado o período de indução, o que pode ser atribuído a miscibilidade limitada da água no óleo (Satyarthi, 2011). A reação teve um início lento, e conforme moléculas de DAG e MAG foram formadas, a miscibilidade de água no óleo foi favorecida, promovendo maior contato entre as fases resultando no aumento da velocidade de reação. Segundo Voll (2012) após certo tempo de reação, os substratos são consumidos e as velocidades de reação se tornam mais lentas, tendendo a zero quando a reação se aproxima da condição de equilíbrio.

Na Figura 3.4 são apresentados os valores calculados pelo modelo para a cinética em batelada alimentada e estes são comparados aos valores experimentais obtidos.

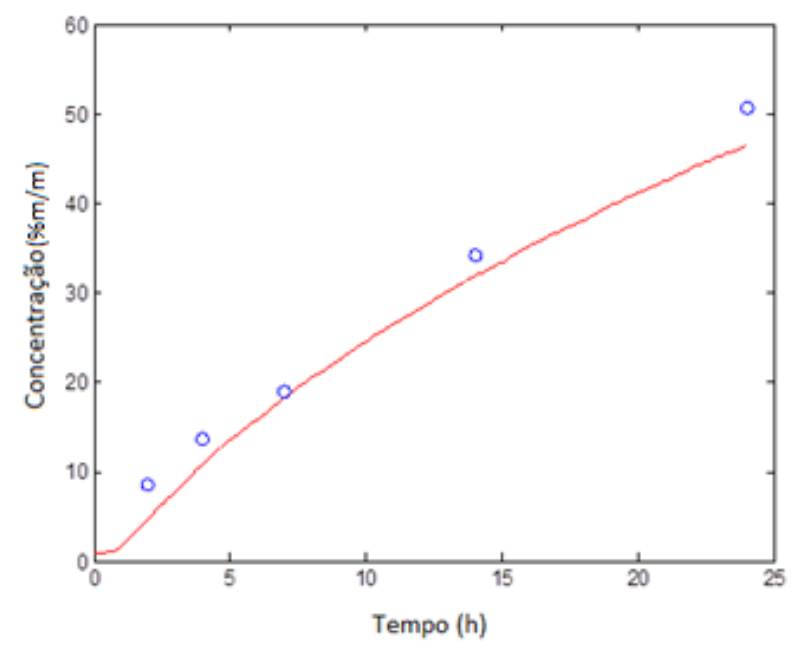

Figura 3.4 - Perfil de ácido graxo livre durante a batelada alimentada, em base livre de água e glicerol. Pontos são dados experimentais e linha contínua dados do modelo.

Estes valores estão apresentados em termos de ácido graxo livre (AGL). A partir desta figura observa-se que os resultados previstos pelo modelo estão de acordo com os valores experimentais. Desta forma, o modelo cinético proposto é capaz de descrever o comportamento desta reação em sistema de batelada alimentada.

Na Figura 3.5 são comparados os perfis da reação de hidrólise do óleo de oliva, em termos de AGL, para as duas abordagem utilizadas - batelada e batelada alimentada. Pode-se observar a diferença entre as abordagem de configuração reacional, principalmente nas primeiras horas de reação. $\mathrm{O}$ uso do sistema batelada alimentada evita o tempo de indução, pois permite o uso de concentração de água suficiente para manter a atividade enzimática favorecendo as reações de hidrólise. Além disso, esta estratégia possibilita a adição de pequenas quantidades de água em intervalos de tempo 
definidos. O que evita o excesso de água no meio reacional diminuindo o efeito de inibição reversível da enzima e propicia maiores valores de acidez livre nas primeiras horas de reação. Corazza et al. (2003) estudaram uma reação de hidrólise enzimática da celobiose para produção de glicose e obtiveram resultados que também indicaram vantagens da utilização de processo em batelada alimentada.

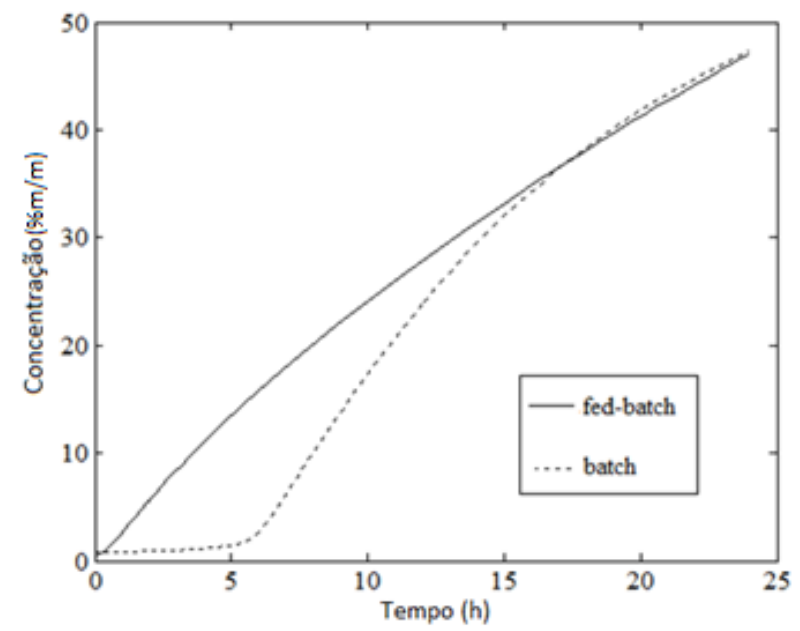

Figura 3.5 - comparação entre batelada com $20 \%$ (verde) e semibatelada (preto) para a mesma quantidade de água alimentada na reação. batelada simulada com $20 \mathrm{~g}$ de água adicionada de uma vez em $100 \mathrm{~g}$ de óleo. semibatelada simulada com $0,825 \mathrm{~g} / \mathrm{h}$ de alimentação de água durante 24 horas. os dois resultados são em ácidos graxos livres.

\section{CONCLUSÕES}

Foi confirmada a influência da concentração inicial de água na seletividade da produção de DAG e no rendimento de AGL. O uso de altas concentrações iniciais de água no meio favorecem a formação de produto com altas concentrações de AGL e menores concentrações de DAG. - O uso de batelada alimentada para introdução água reduz os efeitos de inibição da atividade enzimática e ao mesmo tempo garante a formação dos produtos em tempos mais curtos.

As velocidades iniciais das reações de hidrólise são baixas, e aumentam com a formação de produtos surfactantes. O maior teor de acidez ao final das 24 horas de reação foi obtido no experimento com $20 \%$ de água. Entretanto verificou-se maior acidez nas primeiras horas de reação no experimento com apenas $3 \%$ de água.

O modelo cinético proposto por Voll et al. (2012) e utilizado para descrever a hidrólise enzimática óleo de oliva em sistema batelada e batelada alimentada, em meio livre de solventes, apresentou boa correlação com os dados experimentais obtidos.

De uma maneira geral, no presente trabalho observou-se que a utilização de sistema batelada alimentada em reação de hidrólise enzimática do óleo de oliva pode ser uma alternativa com grande potencial para reduzir os efeitos de inibição enzimática e obter maior rendimento do produto desejado. 


\section{REFERÊNCIAS}

AWADALlAK, J. A.; VOLL, F.; RIBAS, M. C.; SILVA, C.; FILHO, L. C.; SILVA, E. A. Enzymatic catalyzed palm oil hydrolysis under ultrasound irradiation: Diacylglycerol synthesis. Ultrason Sonochem, v.20, p. 1002-1007, 2013.

BABICZ, I. Produção de diacilglicerol via hidrólise enzimática do óleo de palma. Dissertação de mestrado em ciências e tecnologia de processos químicos e bioquímicos da Universidade Federal do Rio de Janeiro, Rio de Janeiro, 2009.

BLASI, F.; COSSIGNANI, L.; SIMONETTI, M.S.; DAMIANI, P. Biocatalysed synthesis of sn-1,3-diacylglycerol oil from extra virgin olive oil. Enzyme Microb. Tech., v. 41, p. 727-732, 2007.

CASTRO, H. F.; MENDES A.A.; SANTOS, J.C.; AGUIAR, C.L., Modificações de óleos e gorduras por biotransformação. Quím. Nova, v. 27, p. 146-156, 2004.

CHEONG, L.Z.; TAN, C.P.; LONG, K.; YUSSOF, M.S.A.; ARIFIN, N.; LO, .K. LAI, O.M. Production of a diacylglycerol-enriched palm olein using lipase-catalyzed partial hydrolysis: Optimization using response surface methodology. Food chem., v. 105, p. 1614-1622, 2007.

CORAZZA, F. de C.; MORAES, F. F.; ZANIN, G. M.; NEITZEL, I. Optimal control in fed-batch reactor for the cellobiose hydrolysis. Acta Sci. Tech., v. 25, p. 33-38, 2003.

FREGOLENTE, P. B. L.; PINTO, G. M. F.; WOLF-MACIEL, M. R.; MACIEL FILHO, R.; BATISTELA, C. B. Produção de monoglicerídeos e diglicerídeos via glicerólise enzimática e destilação molecular. Quím. Nova, v. 32, p. 1539 - 1543, 2009.

FREITAS, L.; BUENO, T.; PEREZ, V.H.; CASTRO, H.F. Monoglicerideos: producao por via enzimatica e algumas aplicacoes. Quim. Nova, v. 31, p. $1514-1521,2008$.

GIOIELLI, L. A. Óleos e gorduras vegetais: composição e tecnologia. Rev. Bras. Farmac., p. $211-232,1995$.

KRISTENSEN, J.B.; XU, X.; MU, H. Diacylglycerol synthesis by enzymatic glycerolysis: Screening of commercially available lipase. J Am. Oil Chem. Soc., v. 82, p. 329-334, 2005.

KRUGUER, R. L.; SYCHOSKI, M.; BALEN, M.; NINOW, J. L.; CORAZZA, M. L. Estudo da glicerólise enzimática na produção de mono e diacilgliceróis utilizando óleo de oliva. Ciênc. Ex. e Nat., v.13, 2011.

MAKI, K. C.; DAVIDSON, M. H.; TSUSHIMA, R.; MATSUO, N.; TOKIMITSU, I.; UMPOROWICZ, D. M.; DICKLIN, M.R.; FOSTER, G.S.; INGRAM, A.; ANDERSON, B.D.; FROST, S.D.; BELL, M. Consumption of diacyglycerol oil as part of a reduced-energy diet enhances loss if body weight and fat in comparison with consumption of a triacyglycerol control oil. Am. J. Clin. Nutri., v. 76, p. 1230-1236, 2002. 
MATOS, L. M.C.; LEALB, I.C.R.; SOUZA, R.O.M.A. Diacylglycerol synthesis by lipase-catalyzed partial hydrolysis of palm oil under microwave irradiation and continuous flow conditions. J. Mol. Catal. B: Enzym, v.72, p. 36-39, 2011.

MURTY, V, R.; BHAT,J.; MUNISWARAN, P. K. A. Hydrolysis of oils by using immobilized lipase enzyme: a review. Biotechnol and Bioprocess Eng. v. 7, 57-66, 2002 .

PAWONGRAT, R.; XU, X.; H-KITTIKUN, A. Synthesis of onoacylglycerol rich in polyunsaturated fatty acids from tuna oil with immobilized lípase AK. Food Chem, v. 104, p. 251-258, 2007.

SANTOS, J. S. Produção de diacilgliceróis a partir da glicerólise enzimática de óleo de peixe utilizando meio com surfactante de grau alimentício. Dissertação de mestrado em engenharia de alimentos da Universidade Federal de Santa Catarina, Florianópolis, 2011.

SATYARTHI, J.K.; SRINIVAS, D.; RATNASAMY, P. Hydrolysis of vegetable oils and fats to fatty acids over solid acid catalysts. Appl Catal A: Gen., v. 391, p. 427-435, 2011.

VALÉRIO, A.; KRUGER, R. L.; NINOW, J. L.; CORAZZA, F. C.; OLIVEIRA, D.; OLIVEIRA, J. V.; CORAZZA, M. L. Kinetics of solvent-free lipase-catalyzed glycerolysis olive oil in surfactant system. J. Agric. and Food Chem., v. 57, p. 83508356, 2009.

VOLL, F. A. P.; ZANETTE, A. F.; CABRAL, V. F.; DARIVA, C.; SOUZA, R. O. M. A.; FILHO, L. C.; CORAZZA, M. L. Kinetic Modeling of Solvent-Free LipaseCatalyzed Partial Hydrolysis of Palm Oil. Appl Biochem. and Biotech., v. 168, p. 11211142, 2012.

YANAI, H.; TOMONO, Y.; ITO K.; FURUTANI N.; YOSHIDA, H.; TADA, N.; Diacylglycerol oil for the metabolic syndrome. Nutri. J., v. 6, p. 43, 2007. 